\title{
REVISÃO DE LITERATURA SOBRE A DANÇA PARA ESTUDANTES COM DEFICIÊNCIA
}

\author{
LITERATURE REVIEW ON DANCE FOR STUDENTS WITH DISABILITIES
}

\author{
Marcus Vinícius Sudário Perez ${ }^{1}$ \\ Christiane Guimarães de Araújo ${ }^{2}$
}

\begin{abstract}
Resumo: Esse texto tem por objetivo apresentar uma breve revisão de literatura, a fim de embasar a pesquisa "Acessibilidade comunicativa corporal: a identidade do movimento de estudantes com deficiência no ensino da dança". Por meio de pesquisa qualitativa, são apresentados alguns conceitos que contribuíram para a compreensão do estudo, como Estado da Arte (Estado do Conhecimento), Revisão Sistemática e Estado da Questão. Como delimitação da referida revisão de literatura, realizou-se estudo descritivo de literaturas sobre a temática dança para estudantes com deficiência, sob a ótica das artes cênicas, no período entre 2015 e 2020. Os descritores utilizados foram: "dança-educação", "dança educação especial", "dança educação inclusiva", "dança e deficiência", "dança e deficiência Campo Grande-MS" e "dança inclusiva em Campo Grande-MS". Como resultado, aponta-se a reflexão sobre 08 estudos selecionados a partir dos critérios de inclusão e exclusão pré-estabelecidos.
\end{abstract}

Palavras-chave: Dança-educação; educação especial; revisão de literatura.

Abstract: This text aims to present a brief literature review in order to support the research "Communicational body for accessibility: the identity of the movement of students with disabilities in dance education", that is in progress and has been carried out by the Grupo de Pesquisa de Poéticas e Educação em Dança (GPPED): Núcleo CRI(s)Es (UEMS). Through qualitative research, we present some concepts that contributed to understanding the study, namely: State of Arte (State of Knowledge), Systematic Review and State of Question. Delimited to a literature review, a descriptive study of literature was made about the theme dance for students with disabilities under the perspective of performing arts in the period between 2015 and 2020. The descriptors used were "dance-education", "dance special education", "dance inclusive education", "dance and disability", "dance and disability Campo Grande-MS" and "inclusive dance in Campo Grande-MS". As a result, the reflection about eight studies selected from the pre-established inclusion and exclusion criteria is pointed out.

Keywords: Dance-education; special education; literature review.

\section{Introdução}

Compreender como se dá o ensino da dança na escola para estudantes ${ }^{3}$ com deficiência é uma das questões preocupantes para a maioria dos profissionais de dança atuantes nas instituições escolares - receamos que acometa desde professores em formação, os já graduados e até mesmo os professores formadores nas licenciaturas. A pergunta que geralmente se ouve a

\footnotetext{
${ }^{1}$ Universidade Estadual de Mato Grosso do Sul, Campo Grande, MS, Brasil.

${ }^{2}$ Universidade Estadual de Mato Grosso do Sul, Campo Grande, MS, Brasil.

${ }^{3}$ Optou-se pela nomenclatura estudante, por considerar essa a pessoa que pratica atividade de estudar de forma ativa, individual e investigativa, quem de fato estuda e dedica-se a algo. Não foi utilizado o termo aluno por causa do entendimento de que este é quem apenas assiste aula, quem muitas vezes recebe a informação de forma coletiva, em salas de aula e passivamente, esperando que todo o conhecimento venha do professor. Outros esclarecimentos sobre essa diferenciação podem ser encontrados em: http://www.ljslaranjeirasdosul.seed.pr.gov.br/modules/noticias/article.php?storyid=87.
} 
respeito é: na disciplina de Arte/dança, na escola, como faço para realmente incluir os estudantes com deficiência em minha aula de dança?

Conhecemos o corpo dito "normal" como aquele que surge de referência apolínea, o qual, para o ensino da dança, teve início no século XX. Este era visto e destinado para corpos clássicos, padronizados segundo o pensamento europeu, que, como descrito no Arquivo Nacional da MAPA (2016), o Imperial Instituto dos Meninos Cegos, fundado em 1854 no Rio de Janeiro, foi idealizado a partir dos moldes europeus experienciados pelo professor de história José Alvares de Azevedo, em Paris.

Porém, ao considerarmos o ideal de corpo padrão - aquele teoricamente sem deficiência - e colocarmo-nos diante do que comumente presenciamos em escolas cujos estudantes com deficiência adaptam-se ao universo das pessoas sem deficiência, reputamos nesse estudo a compreensão de que o contrário seria o mais pertinente a acontecer, a por nós nomeada adaptação inversa. Propomos o termo 'adaptação inversa' como o processo ensinoaprendizagem, que, ao acontecer na aula prática de dança presente na disciplina de Arte, tenha como referencial o estudante com deficiência, enquanto os outros estudantes, sem deficiência, adaptam-se ao universo de condições especiais, tanto físicas como cognitivas.

A partir disso, constatamos a necessidade de realizar uma revisão de literatura sobre o escopo teórico que desejávamos pesquisar. Buscamos estudos referentes à "inclusão na dança educação" nos bancos de dados do Scientific Electronic Library Online (SciELO), da Biblioteca Digital Brasileira de Teses e Dissertações (IBICT) e nos repositórios da Universidade Católica Dom Bosco (UCDB), da Universidade Federal de Mato Grosso do Sul (UFMS) e da Universidade Estadual de Mato Grosso do Sul (UEMS). Delimitamos por trabalhos realizados no período de janeiro de 2015 a janeiro de 2020, por ser o período de estudos e implantação da Base Nacional Comum Curricular (BNCC) no Brasil.

Os critérios de inclusão foram: pesquisas que retratavam dança-educação; dança na educação especial e inclusiva em Campo Grande/MS; estudos publicados sobre a temática no período entre 2015 e 2020; ensino de dança no ensino formal; e, por fim, estudos publicados em língua portuguesa no Brasil.

Os critérios de exclusão foram: escolas especiais específicas para estudantes com deficiência; ensino não-formal; estudos publicados em âmbito internacional e em línguas estrangeiras; e estudos na área da Educação Física.

Por ser uma revisão de literatura com o objetivo de mapear as pesquisas já realizadas na área, preocupamo-nos então, assim como orienta Marli André (2010), em não entendermos a revisão de literatura como referencial teórico, mas sim como aquela que nos fará passar a fase inicial da pesquisa, assimilando que, no percurso do referencial teórico nela encontrado, constituiremos consistente teorização e crítica para a construção de conhecimento acerca da temática pesquisada.

Sabemos, no entanto, que os autores apontam e divergem na utilização de diferentes nomenclaturas para esse levantamento de estudos e pesquisas. Fora o termo revisão de literatura, encontramos também terminologias como Estado da Arte (ou Estado do Conhecimento), Revisão Sistemática e Estado da Questão. No que tange às variantes do que é entendido como revisão de literatura, encontramos ramificações que a caracterizam como revisão narrativa, revisão integrativa, revisão sistemática e revisão sistemática de literatura.

Buscamos assim, a partir do termo Revisão de Literatura, entender as diferenças entre essas variantes. Segundo Rother (2007), algumas diferenças definem com clareza os conceitos definidos sobre Revisão Narrativa (RN) e Revisão Sistemática (RS). Os estudos pautados pela $\mathrm{RN}$ abrangem, de maneira mais ampliada, os assuntos a serem pesquisados pelos autores. Os artigos pautados nessa abordagem, geralmente fazem parte da metodologia denominada Estado da Arte, entendida como o estudo que acontece a partir da decisão dos pesquisadores de não 
especificarem determinados pontos da pesquisa, a fim de compreenderem de forma abrangente sobre o que já foi estudado sobre a temática.

Diferentemente dessa metodologia, a Revisão Sistemática (RS) aponta especificidades nos tópicos estudados, caracterizando-se como uma pesquisa que conhecemos como Estado da Questão. A Revisão Integrativa (RI) assemelha-se à RS em diversas características, mas diferenciam-se durante o processo metodológico de cada uma.

De modo distinto da Sistemática, a RI permite a inserção de outros estudos, para além de pesquisas, como revisões teóricas e relatos de experiência. A Revisão Sistemática de Literatura (RSL) também se aproxima dos conceitos estabelecidos para a RS, mas diferencia-se pela maneira analítica dos resultados. A fim de apontarmos com maior clareza as diferenças entre elas, organizamos o quadro abaixo.

\begin{tabular}{|c|c|c|}
\hline $\begin{array}{c}\text { REVISÃO } \\
\text { NARRATIVA }\end{array}$ & REVISÃO INTEGRATIVA & $\begin{array}{c}\text { REVISÃO SISTEMÁTICA DE } \\
\text { LITERATURA }\end{array}$ \\
\hline $\begin{array}{l}\text { Os artigos de revisão narrativa } \\
\text { são publicações amplas, } \\
\text { apropriadas para descrever e } \\
\text { discutir o desenvolvimento ou } \\
\text { o "estado da arte" de um } \\
\text { determinado assunto, sob } \\
\text { ponto de vista teórico ou } \\
\text { contextual. As revisões } \\
\text { narrativas não informam as } \\
\text { fontes utilizadas, a } \\
\text { metodologia para busca das } \\
\text { referências, nem os critérios } \\
\text { utilizados na avaliação e } \\
\text { seleção dos trabalhos. } \\
\text { (ROTHER, 2007, p. 1). }\end{array}$ & $\begin{array}{l}\text { É uma revisão que também } \\
\text { utiliza métodos explícitos e } \\
\text { sistemáticos para analisar } \\
\text { tendências, sintetizar resultados, } \\
\text { identificar, selecionar e avaliar } \\
\text { não só estudos primários } \\
\text { (pesquisas), como revisões } \\
\text { teóricas, relatos e outros tipos de } \\
\text { estudos. A questão de pesquisa é } \\
\text { mais ampla do que aquela que } \\
\text { gera uma revisão sistemática, } \\
\text { pois pode reunir vários tipos de } \\
\text { estudos (teóricos/quant/quali) } \\
\text { [...]. (MARTINS, 2018; p. 15). }\end{array}$ & $\begin{array}{l}\text { [...] o objetivo da revisão } \\
\text { sistemática de literatura (RSL) } \\
\text { é formar um arcabouço tanto } \\
\text { teórico como prático dos } \\
\text { artefatos que foram utilizados } \\
\text { para a solução de } \\
\text { determinados problemas em } \\
\text { estudos primários, e analisar } \\
\text { em que condições } \\
\text { determinados artefatos foram } \\
\text { utilizados para solucionar um } \\
\text { determinado problema[...]. } \\
\text { (BRIZOLA; FANTIN, 2016, } \\
\text { p. 37). }\end{array}$ \\
\hline
\end{tabular}

Quadro 1: Quadro das diferentes variantes de Revisão de Literatura - Fonte: Organizado pelos autores.

Ao considerarmos os conceitos apresentados na Quadro 1, compreendemos que nenhum deles abarca por completo a metodologia de pesquisa imbricada nessa revisão de literatura. Então, ao aprofundarmos os estudos sobre seus possíveis procedimentos metodológicos, encontramos, juntamente com os conceitos de Estado da Questão e Estado da Arte, estudos voltados à terminologia Revisão Sistemática (RS).

O Estado da Arte (EA) avalia todo o aparato científico existente sob a visão de determinada área de pesquisa, deferida pelo pesquisador com a finalidade de, ao longo dos anos, tornar notória a evolução sobre os estudos desenvolvidos acerca do que foi escolhido para o levantamento. Por ser uma pesquisa de caráter qualitativo e quantitativo, propõe também o levantamento das possíveis lacunas existentes sobre a área pesquisada, notando e corroborando com questões ainda não pesquisadas ou devidamente aprofundadas naquele campo.

A Revisão Sistemática (RS), por sua vez, tem como finalidade analisar dados publicados de determinada área de pesquisa, mediante método sistematizado de busca, com a utilização de descritores específicos que facilitam o levantamento de informações, visando a especificidade do assunto abordado. Está pautada na pesquisa por meio de bases de dados, utilizando critérios 
de inclusão e exclusão pré-definidos pelo pesquisador do tema. Apesar de ser uma metodologia de trabalho independente, a RS também está presente no levantamento de dados tanto das pesquisas realizadas no Estado da Arte como no Estado da Questão.

O Estado da Questão (EQ) visa entender a situação atual dos estudos desenvolvidos sobre determinado objeto de pesquisa no cenário científico. É a partir dele que o pesquisador alcança o domínio da literatura (NÓBREGA-THERRIEN; THERRIEN, 2004), sendo capaz de, por meio de seu levantamento bibliográfico, discorrer sobre a área pesquisada e desenvolver um pensamento crítico em articulação com sua proposta de estudo.

Postos alguns conceitos definidos pelas autoras, nos auxilia no esclarecimento do porquê estamos pesquisando a dança para estudantes com deficiência na rede regular de ensino caracterizando assim o objeto de investigação dessa pesquisa -, quais os achados científicos nessa área abordam dança no contexto escolar, educação especial/educação inclusiva.

Esclarece também o entendimento sobre dança na educação inclusiva em Mato Grosso do Sul, por meio do levantamento bibliográfico realizado em bancos de dados pré-definidos, que contribui para a localização do objeto de estudo e elaboração das categorias de análise, tornando possível a articulação dos estudos já existentes na área de dança na educação especial/inclusiva com a discussão proposta no atual estudo. Dessa forma, o presente estudo caracteriza-se como uma revisão de literatura como caminho para compor a base teórica da pesquisa.

Olhar para a perspectiva de adaptação inversa, proposta nessa revisão de literatura, é, antes de mais nada, olhar para uma nova forma de fazer e ver a educação, um novo formato de trabalhar com a dança na disciplina de Arte, novas concepções de ensino e aprendizado para inserir o estudante com deficiência no processo artístico. Considerando ser uma forma inovadora de pensar as aulas de dança na escola, buscamos por essa definição.

Segundo Araújo (2018), a educação inovadora é

[...] aquela que promove uma ruptura da forma tradicional de ensinar e aprender, compreendendo o conhecimento por uma perspectiva epistemológica que problematiza os procedimentos educativos e prioriza a criatividade, autonomia e valores como respeito, autoestima, valorização do outro no meio social e a mediação do professor com vistas a aprendizagens significativas. (ARAÚJO, 2018, p. 29).

Um dos objetivos propostos à futura aplicabilidade dessa pesquisa, é proporcionar aos estudantes com deficiência a oportunidade de conhecerem a identidade de seus movimentos e, consequentemente, de seus corpos. A educação inovadora, ao propor um processo ensinoaprendizagem, trabalha o sujeito para além dos saberes educacionais, promovendo o desenvolvimento afetivo, cognitivo e social do estudante.

É nesse sentido que Moran (2012) analisa e defende que a escola e a sociedade não são tão diferentes, tendo em vista que, em ambos os convívios, estão presentes as mesmas pessoas que as compõem e que "A escola pode arriscar mais, permitir-se aprender com os erros e buscar o desconhecido, ao menos em parte”. (MORAN, 2012, p. 68).

\section{Educação especial e inclusiva no decorrer das Leis Brasileiras}

Em 1961, a Lei n. 4.024, de Diretrizes e Bases da Educação Nacional - LDB, fundamentou o atendimento educacional a pessoas com deficiência. Naquela época, estas eram tratadas como "excepcionais", mas a Lei garantia sua inserção no "sistema geral de Educação, a fim de integrá-los na comunidade". Essa problemática, pautava-se nas propostas do Paradigma da Institucionalização (PdI), cuja característica predominante era a manutenção de 
pessoas com deficiência em instituições conhecidas como "escolas especiais". Esses eram espaços que contrapunham o ideal de inserção social, porque segregavam os estudantes com deficiências intelectuais, motoras e cognitivas.

A Lei n. 5.692, segunda LDB (1971), época de grandes retrocessos no país, que inclusive substituiu a anterior, considerava que os estudantes com deficiências físicas ou mentais, bem como aqueles com atraso considerável em relação à idade regular de matrícula e os superdotados, deveriam receber tratamento especial. Novamente, o documento destinava as escolas especiais como as únicas capazes de proporcionar o processo ensino-aprendizagem para crianças com deficiência, reafirmando a não-inserção de pessoas com deficiência nas escolas regulares de ensino.

No que tange à educação apresentada na Constituição Federal (1988), esta propõe que os processos educativos devem acontecer em três âmbitos, a família, a escola e a sociedade, e seu artigo 208, ao abordar sobre a educação básica obrigatória e gratuita, dispõe que é compromisso do Estado garantir "atendimento educacional especializado aos portadores de deficiência, preferencialmente na rede regular de ensino".

É salutar, porém, dizer que atualmente o termo "portadores de deficiência" não é mais utilizado, pois o significado da palavra "portar" diz respeito ao ato de carregar ou levar algo consigo. Diferentemente do celular, por exemplo, que portamos e deixamos quando queremos, pessoas com deficiências cognitivas, motoras ou intelectuais não deixam suas características de lado quando por assim optarem.

Ainda em contexto legal, a LDB n. 9394/1996, atualmente em vigor, possui um capítulo específico para a educação especial, que dispõe sobre a utilização necessária de serviços de apoio especializado nas redes regulares de ensino, visando atender às demandas de alunos com deficiência. No entanto, é notório que o fato de alunos com deficiência estarem matriculados em instituições regulares de ensino não garante sua inclusão na sociedade e contexto escolar.

Ao apresentar considerações a respeito da inclusão, Ferreira (2005) discorre que, para ser efetiva, a educação inclusiva deve considerar a individualidade do sujeito, levando em consideração sua diversidade, para assim estabelecer uma aprendizagem inclusiva que abarque todos em questão.

A inclusão, foco desse estudo, é vista sob o prisma da educação especial. É por meio dela que objetivamos entender como a dança acontece ou não nas escolas básicas. Para pesquisarmos estudos sobre a deficiência nas aulas de dança no contexto escolar, buscamos primeiramente a diferença entre aula de dança na educação especial e na educação inclusiva.

Segundo Silva (2010, p. 9), “A educação especial é uma área de conhecimento e também uma modalidade de ensino que tem como objetivo o desenvolvimento de práticas e estratégicas pedagógicas voltadas pra os alunos com necessidades educacionais especiais". Já a educação inclusiva, que iniciou no Brasil em meados da década de 1990, propõe um novo modelo de atendimento escolar para estudantes com deficiência. Esse termo é entendido como aquele que acolhe todas as pessoas, sem exceção, seja um estudante com deficiência física, com comprometimento mental, superdotados ou com diferentes síndromes. Ou seja, é aplicado às minorias que, de alguma forma, necessitam de cuidado e olhar especial em seu processo de aprendizagem, juntamente com aqueles que não demonstram deficiência aparente ou reconhecida pelo sistema de saúde.

Nesse prisma, as aulas de dança são pensadas, a priori, a partir das possibilidades dos estudantes com deficiência, para que os estudantes sem deficiência se incluam naquele contexto - por isso nomeamos de adaptação inversa. Dessa maneira, as especificidades de cada indivíduo ditam as conduções e mediações entre professor e aluno.

A escola, nesse contexto de educação inclusiva, gera, na relação de conteúdos, oportunidades de compreensão de todos os estudantes, em suas maiores ou menores diferenças e níveis de abstração de pensamento e condições especiais. 
Por entendermos que todas as coisas criadas foram pensadas como extensão do corpo humano, não podemos desconsiderar as bengalas, as cadeiras de roda e os aparelhos auditivos como extensões dos corpos dos estudantes com deficiência. Para fins de consideração, caminhamos no panorama da educação sensível mediante a experiência proposta pelos sentidos, como argumenta Larrosa (2002). É necessário facilitarmos aos estudantes deficientes outra perspectiva de seus corpos marginalizados, buscando uma identidade corporal que proporcione às pessoas que vivem em contexto diferente das sem deficiência outras maneiras de comunicação corporal com o mundo.

\section{A influência dos paradigmas corporais na relação entre dança e educação inclusiva}

Nossa convicção de que a educação se dá pelo corpo, parte do diálogo com as autoras Cazé e Oliveira (2008) quando discorrem que "o movimento é a nossa primeira forma de linguagem: uma linguagem não verbal estruturada no corpo". Para além, as autoras Santos e Figueiredo (2003) avaliam a presença da dança no contexto escolar como uma área de aprendizado e potencial transformadora das experiências sensíveis, motoras e cognitivas dos estudantes. Entendendo a dança como linguagem artística capaz de transformar o corpo do sujeito em corpo ativo, potente e comunicativo, por que não explorarmos a dança para estudantes com deficiência com o mesmo intuito? Segundo as autoras Falsarella e Bernardes-Amorim (2008),

[...] Por ser uma atividade coletiva e lúdica, acredita-se que a dança seja um instrumento de facilitação nos relacionamentos interpessoais, no desenvolvimento da autoestima, da autoconfiança e do senso de responsabilidade. Também proporciona benefícios físicos como: aumento da resistência corporal, estética, postura e flexibilidade; além de contribuir para o equilíbrio emocional dentro de um desenvolvimento do indivíduo como um todo. (FALSARELLA; BERNARDES-AMORIM, 2008, p. 308).

A singularidade dos corpos, bem como suas diferenças, só começou a ser notada com o início da dança moderna, quando houve a desconstrução dos paradigmas corporais. Nesse contexto, Albright (2012) propõe, então, uma revisão de conceitos pré-estabelecidos historicamente no ensino da dança no qual pautam o corpo magro, alto e flexível como um corpo capaz de dançar - questões sociais abarcadas pelos corpos não-normativos. Apesar dessas discussões ocorrerem desde o início da era moderna, somente na dança contemporânea que essas pesquisas tomaram forma e relevância de estudo.

Nunes (2005) defende que a dança contemporânea propõe um desdobramento das diferenças, propagando um corpo-diferente, aquele que foge dos padrões etéreos dos bailarinos clássicos, que desafia o ensino da dança e possibilita a existência e a representatividade de uma "assimetria". Compreendemos assim, que os princípios da dança contemporânea seriam os caminhos para o trabalho transformador da linguagem da dança na escola com estudantes com e sem deficiência.

No entanto, identificamos que um dos principais embates, assim como com a maioria dos profissionais da dança nas escolas, está no modelo tradicional e tecnicista instaurado na educação brasileira, inclusive sendo este o que carrega a ideia de que "o bom aluno é aquele que não se move, que fica quieto e sentado na carteira".

As instituições escolares no Brasil tendem a reprimir os movimentos dos estudantes dentro do ambiente escolar, pautando-se no ideal de que estudante disciplinado é um estudante imóvel e, consequentemente, obediente. Em “A Educação e a fábrica de corpos”, Strazzacappa (2001, p. 70) salienta que 
O movimento corporal sempre funcionou como uma moeda de troca. [...]Professores e diretores lançam mão da imobilidade física como punição e da liberdade de se movimentar como prêmio. Constantemente, os alunos indisciplinados (lembrando que muitas vezes o que define uma criança indisciplinada é exatamente o seu excesso de movimento) são impedidos de realizar atividades no pátio, seja através da proibição de usufruir do horário do recreio, seja através do impedimento de participar da aula de educação física, enquanto que aquele que se comporta pode ir ao pátio mais cedo para brincar.

A discussão sobre a movimentação corporal dentro das escolas ainda vai além. Se para os estudantes sem deficiência o movimento já é algo barrado pela instituição, qual função desempenha o movimento com estudantes com deficiência, que naturalmente já possuem suas limitações físicas e cognitivas de movimentação? Um fato que, na maioria das vezes, afasta ao invés de aproximar - sua "inclusão" nos contextos escolares.

\section{Estudos encontrados sobre a relação entre dança-educação e deficiência}

Para tecermos abordagem sobre inclusão de estudantes com deficiência no ensino da dança, estabelecemos o período e dividimos o estudo de revisão de literatura em três categorias. O período pré-estabelecido de 2015, ano de publicação da primeira versão da Base Nacional Comum Curricular (BNCC), até os dias atuais (2020). Sobre as categorias, a primeira abarca a "Dança no contexto escolar"; a segunda aborda a "Educação em dança no viés da educação especial"; e, por fim, a terceira categoria de busca está pautada nos achados sobre "Dança inclusiva em Campo Grande/MS".

Na primeira versão da BNCC, logo em seus primeiros capítulos, apresenta seção dedicada especificamente à "educação especial na perspectiva inclusiva" (BRASIL, 2015, p. 11). Durante o texto, apresenta a necessidade de cumprir as medidas necessárias para a completa inserção de estudantes com deficiência em instituições escolares, elencando tópicos que tratam especificamente sobre a acessibilidade nas instituições escolares, para o cumprimento do ato de ir e vir, o Atendimento Educacional Especializado (AEE) e, consequentemente, a inserção de profissionais de apoio dentro das escolas.

Apesar de ser considerada um avanço, a BNCC de 2015 ainda comete erros ao apontar terminologias, como "classes comuns", por exemplo, abrem brechas para um pré-conceito estabelecido há anos, quando as classes comuns eram consideradas como aquelas que não possuíam estudantes com deficiência, o que reforça o estereótipo de corpo normativo social.

No capítulo sobre educação especial sugere diversos caminhos para a inserção do estudante com deficiência no contexto escolar. Ao abordar sobre as possíveis estratégias para um enriquecimento curricular, sugere-se que projetos de artes, ciências e esportes sejam propostas de desenvolvimento e expansão do conhecimento e da autonomia dos estudantes com deficiência. Há uma mínima consciência da importância da Arte no desenvolvimento físico, afetivo, cognitivo e intelectual desses estudantes, mas o documento deixa lacunas ao não se aprofundar nessas perspectivas.

A partir da disponibilização da BNCC, o foco dessa revisão de literatura é acompanhar na área das Artes, especificamente a dança, quais foram os avanços dos estudos sobre a dança na escola básica nos últimos anos. Para isso, estabelecemos as categorias "Dança no contexto escolar", utilizando a palavra-chave "dança-educação" no qual encontramos no SciELO 6 estudos em português, sendo 4 estudos no escopo teórico da Educação Física e 2 sobre a perspectiva do ensino da dança no ensino não-formal - resultado de exclusão levando em consideração os critérios estabelecidos. 
$\mathrm{Na}$ BDTD encontramos 3 estudos filtrados da mesma maneira, sendo todos voltados ao ensino da dança no ensino formal. No repositório UCDB encontramos 2 estudos, sendo 1 da área de Educação Física, levando à exclusão do mesmo.

Nos repositórios UFMS e da UEMS não encontramos estudos com os descritores utilizados durante o período pesquisado. Ao final, levando em consideração os critérios de exclusão e inclusão, selecionamos 4 artigos dos 10 encontrados.

$\mathrm{Na}$ categoria "Educação em dança na perspectiva da educação especial", utilizamos os descritores "dança educação especial", "dança educação inclusiva" e "dança e deficiência". Na base de dados da SciELO encontramos 2 estudos, na BDTD encontramos 3 estudos, tendo 2 selecionados e 1 excluído; e no repositório da UCDB encontramos 1 estudo sob a ótica da Educação Física. Novamente, nos repositórios da UFMS e da UEMS não encontramos estudos durante a filtragem da pesquisa. Assim selecionamos 4 artigos dos 6 encontrados.

$\mathrm{Na}$ categoria "Dança inclusiva em Campo Grande/MS", utilizamos na busca os descritores "dança e deficiência Campo Grande-MS" e "dança inclusiva em Campo GrandeMS". Como a pesquisa estabelece recortes específicos, é notória a escassez de estudos nas áreas observadas. Nessa categoria, em especial, encontramos apenas 1 estudo, pelo viés da Educação Física, no repositório da UCDB, posteriormente descartado. Nos demais bancos de dados, nada encontramos a partir das palavras-chave utilizadas.

Para melhor organização dessa coleta de dados, apresentamos o Quadro 3, que demonstra as especificidades de cada categoria pesquisada, incluindo apenas os artigos selecionados de acordo com os critérios de inclusão e exclusão.

\begin{tabular}{|c|c|c|}
\hline \multicolumn{3}{|l|}{$\begin{array}{c}\text { CATEGORIA 1: } \\
\text { Dança no contexto escolar }\end{array}$} \\
\hline REFERÊNCIA BIBLIOGRÁFICA & ANO & $\begin{array}{l}\text { BANCO DE } \\
\text { DADOS }\end{array}$ \\
\hline $\begin{array}{l}\text { PINHO, E. P. B. Performances da dança-educação: autonomia } \\
\text { e autogovernança. 2015. } 188 \text { f. Dissertação (Mestrado em } \\
\text { Performance Cultural) - Universidade Federal de Goiás, } \\
\text { Goiânia, 2015. }\end{array}$ & 2015 & $\begin{array}{l}\text { Biblioteca Digital } \\
\text { Brasileira de Teses } \\
\text { e Dissertações } \\
\text { (BDTD) }\end{array}$ \\
\hline $\begin{array}{l}\text { QUADROS, Cláudia Terezinha. Contribuições dos processos } \\
\text { coreográficos da dança-educação à formação docente: } \\
\text { ensinar/aprender em coreografias didático-criativas. 2017. } 194 \text { f. } \\
\text { Tese (Programa de Pós-Graduação em Educação) - Universidade } \\
\text { Federal de Santa Maria, Santa Maria, 2017. }\end{array}$ & 2017 & $\begin{array}{l}\text { Biblioteca Digital } \\
\text { Brasileira de Teses } \\
\text { e Dissertações } \\
\text { (BDTD) }\end{array}$ \\
\hline $\begin{array}{l}\text { HOLANDA, Rafaela Eleutério. Dança-sujeito-encontro: } \\
\text { experiências em dança-educação na Escola Parque Anísio Teixeira - } \\
\text { Ceilândia/DF. 2018. } 111 \text { f., il. Dissertação (Mestrado Profissional } \\
\text { em Arte) - Universidade de Brasília, Brasília, } 2018 .\end{array}$ & 2018 & $\begin{array}{l}\text { Biblioteca Digital } \\
\text { Brasileira de Teses } \\
\text { e Dissertações } \\
\text { (BDTD) }\end{array}$ \\
\hline $\begin{array}{l}\text { ARAUJO, Christiane Guimarães de; REBOLO, Flavinês } \\
\text { (Orient.). Um contexto inovador: a arte como base para o } \\
\text { processo ensino-aprendizagem na educação básica. 2018. Tese } \\
\text { (Doutorado em Educação) - Universidade Católica Dom Bosco, } \\
\text { Campo Grande, } 2018 .\end{array}$ & 2018 & $\begin{array}{l}\text { Repositório } \\
\text { Universidade } \\
\text { Católica Dom } \\
\text { Bosco (UCDB) }\end{array}$ \\
\hline
\end{tabular}




\begin{tabular}{|c|c|c|}
\hline \multicolumn{3}{|c|}{$\begin{array}{l}\text { CATEGORIA 2: } \\
\text { Educação em dança na perspectiva da Educação Especial }\end{array}$} \\
\hline REFERÊNCIA BIBLIOGRÁFICA & ANO & $\begin{array}{l}\text { BANCO DE } \\
\text { DADOS }\end{array}$ \\
\hline $\begin{array}{l}\text { CUNHA, G. B. Dança inclusiva e deficiência intelectual: um } \\
\text { estudo com educandos da rede municipal de ensino de Aparecida } \\
\text { de Goiânia. 2017. } 96 \text { f. Dissertação (Mestrado em Ensino na } \\
\text { Educação Básica) - Universidade Federal de Goiás, Goiânia, } 2017 .\end{array}$ & 2017 & $\begin{array}{l}\text { Biblioteca Digital } \\
\text { Brasileira de Teses e } \\
\text { Dissertações } \\
\text { (BDTD) }\end{array}$ \\
\hline $\begin{array}{l}\text { PAULINO, Belister Rocha. Movimento, arte e expressividade: } \\
\text { uma proposta de dança educativa para alunos com deficiência } \\
\text { intelectual. 2017. } 131 \text { f., il. Dissertação (Mestrado Profissional } \\
\text { em Arte) - Universidade de Brasília, Brasília, } 2017 .\end{array}$ & 2017 & $\begin{array}{l}\text { Biblioteca Digital } \\
\text { Brasileira de Teses } \\
\text { e Dissertações } \\
\text { (BDTD) } \\
\end{array}$ \\
\hline $\begin{array}{l}\text { ANJOS, Isabelle de Vasconcellos Corrêa dos; FERRARO, } \\
\text { Alexandre Archanjo. A influência da dança educativa no } \\
\text { desenvolvimento motor de crianças. Rev. paul. pediatr., v. 36, } \\
\text { n. 3, São Paulo, jul./set. 2018. Disponível em: } \\
\text { https://doi.org/10.1590/1984-0462/;2018;36;3;00004. }\end{array}$ & 2018 & SciELO \\
\hline $\begin{array}{l}\text { GILBERT, Ana Cristina Bohrer; KELLERMAN, Paulo. } \\
\text { Geografias corporais: dança, corpo e deficiência. Interface, } \\
\text { Botucatu, v. 24. Botucatu, abril/2020. Disponível em: } \\
\text { https://doi.org/10.1590/interface.190603. }\end{array}$ & 2020 & SciELO \\
\hline \multicolumn{3}{|l|}{$\begin{array}{c}\text { CA TEGORIA 3: } \\
\text { Dança inclusiva em Campo Grande/MS }\end{array}$} \\
\hline $\begin{array}{l}\text { Não foram encontrados estudos referentes aos descritores utili } \\
\text { período de 2015-2020 nos bancos de dados utilizados. }\end{array}$ & & pesquisa entre o \\
\hline
\end{tabular}

Quadro 3: Especificidades de cada categoria pesquisada - Fonte: Organizado pelos autores.

Entre os estudos encontrados, Pinho (2015), estabelece debate sobre a prática do professor de dança na escola pública pautando-se em dois processos de ensino e aprendizagem a partir da dança-educação: o ensino crítico e o ensino tecnicista. Também discorre sobre as possíveis problematizações dos estudantes e seus contextos sociais.

Quadros (2017), por sua vez, discorre sobre o processo ensino-aprendizagem por meio de coreografias didático-criativas como impulsionadoras do ato criativo entre professores e estudantes. Aborda as contribuições do processo coreográfico na relação entre educadora e educando, trabalhando as funções cognitivas e motoras das redes de compartilhamento entre corpos. Já Holanda (2018), a partir das falas dos estudantes atuantes em oficinas e aulas de dança, investiga as vivências obtidas no processo ensino-aprendizagem da dança em instituições escolares. Por sua vez, Araújo (2018), durante sua tese, analisou a Arte como área de conhecimento capaz de estabelecer, por meio de criatividade, imaginação e metáforas, integração entre as demais áreas do conhecimento, transformando-a assim na base do processo ensino-aprendizagem em escolas inovadoras.

A partir do estabelecimento de um diálogo entre dança e educação inclusiva, Cunha (2017) investiga quais contribuições a dança pode proporcionar aos estudantes com deficiência intelectual, visando sua inclusão no âmbito social e educativo. No decorrer das reflexões, notamos semelhanças entre a pesquisa de Cunha (2017) e Paulino (2017), que, por sua vez, 
investiga como a experimentação de movimentos corporais instigados pela dança no contexto escolar impulsiona o desenvolvimento da expressividade de estudantes com deficiência intelectual, considerando até a função do professor como mediador desse processo.

Gilbert (2018) traça uma reconfiguração do corpo considerado "normal" e, consequentemente, capacitado para dançar. Utilizando-se da fotografia e da literatura, além da dança, a autora proporciona o diálogo entre as diversas corporeidades e suas geografias a partir da experiência em dança proporcionada a estudantes com deficiência. Anjos e Ferraro (2018) comparam as diferenças propiciadas ao desenvolvimento motor de crianças atuantes em proposta de dança educativa em contraponto com crianças que não participaram dela. Oito meses depois, as autoras voltaram a revisitar os resultados obtidos, constatando a permanência dos ganhos no desenvolvimento das mesmas crianças.

Contudo, apesar de as autoras abordarem a dança no contexto escolar e a educação em dança na perspectiva da educação especial - mesmo já notório a falta de estudos dedicados ao locus específico desse estudo -, nenhuma delas desenvolve estudos que abordam propostas facilitadoras para as práticas de professores dentro das escolas.

Sendo assim, a continuação da pesquisa, a partir dessa revisão de literatura, buscará desenvolver estudos de dança voltados para estudantes com deficiência, aplicando-os com o propósito de verificar sua viabilidade sobre a 'adaptação inversa' proposta nesse estudo como uma possibilidade real de inclusão das práticas corporais das aulas de dança na disciplina de Arte.

\section{Considerações finais}

Essa revisão contribuiu para esclarecermos os eixos teóricos norteadores da continuação da pesquisa delimitados a partir das categorias estabelecidas, algo que gerou considerações importantes para a concepção do escopo desse trabalho. Permitiu-nos compreender o referencial teórico, mostrando-nos a urgência de pesquisas sobre essa temática com outra perspectiva e olhar.

Podemos notar, a partir delas e dos descritores utilizados, que nos anos 2016 e 2019 não foram publicados estudos que abordam a temática pesquisada. Nos anos 2015, 2017, 2018 e 2020 não houve mais que 03 trabalhos publicados sobre a mesma temática, o que evidencia a importância de novas pesquisas abordarem as questões imbricadas no ensino da dança para estudantes com deficiência.

Ao pesquisarmos sobre o locus da pesquisa nos bancos de dados utilizados, percebemos que não há estudos publicados acerca do ensino da dança na educação especial e inclusiva em Campo Grande-MS - ressaltando que três, dos cinco bancos de dados, são de universidades presentes em Mato Grosso do Sul.

Tendo em vista os aspectos observados, o referencial teórico abre brechas para o desenvolvimento de questões não abordadas nos estudos pesquisados. Dentre eles, a adaptação inversa, proposta nesse estudo, que propõe pensar planos de aula de dança que funcionem como facilitadores da inclusão plena de estudantes com deficiência dentro do contexto escolar, a fim de que possa proporcionar uma consciência corporal a partir da descoberta da identidade de seus movimentos e gere sua autonomia.

\section{Referências}

ALBRIGHT, Ann Cooper. Movendo-se através da diferença: dança e deficiência. Revista Cena, n. 12. 2012. 
ANDRÉ, Marli. Pesquisa sobre Formação de Professores. Síntese do II Simpósio de grupos de pesquisa do GT 8 da ANPEd. Form. Doc., Belo Horizonte, v. 02, n. 03, p. 152-159, ago./dez. 2010. Disponível em: http://formacaodocente.autenticaeditora.com.br.

ANJOS, Isabelle de Vasconcellos Corrêa dos; FERRARO, Alexandre Archanjo. A influência da dança educativa no desenvolvimento motor de crianças. Rev. Paul. Pediatr. v. 36, n. 3, São Paulo, jul./set. 2018. Disponível em: https://doi.org/10.1590/1984-0462/;2018;36;3;00004.

ARAÚJO, Christiane Guimarães de. Um contexto inovador: a arte como base para o processo ensino-aprendizagem na educação básica. Tese Doutorado em Educação, Universidade Católica Dom Bosco, 2018.

BONDÍA, Jorge Larrosa. Notas sobre a experiência e o saber de experiência. Revista Brasileira de Educação, Rio de Janeiro, n. 19, p. 20-28, jan./abr. 2002.

BRASIL. Base Nacional Comum Curricular. Brasília: MEC, 2015. Disponível em: basenacionalcomum.mec.gov.br/images/relatorios-analiticos/BNCC-APRESENTACAO. pdf. Acesso em: 29 de abril de 2020.

BRASIL. Constituição Federal, de 5 de outubro de 1988. Disponível em: http://www.planalto.gov.br/ccivil_03/Constituicao/Constituicao.htm. Acesso em: 28 de abril de 2020.

BRASIL. Lei n. 4.024, de 20 de dezembro de 1961. Fixa as Diretrizes e Bases da Educação Nacional. Disponível em: http://www.planalto.gov.br/ccivil_03/leis/L4024.htm. Acesso em: 28 de abril de 2020.

BRASIL. Lei n. 5.692, de 11 de agosto de 1971. Fixa Diretrizes e Bases para o ensino de $1 .^{\circ}$ e $2 .^{\circ}$ graus, e dá outras providências. Disponível em: http://www.planalto.gov.br/ccivil_03/Leis/L5692.htm. Acesso em: 28 de abril de 2020.

BRASIL. Lei n. 9.394, de 20 de dezembro de 1996. Estabelece as Diretrizes e Bases da Educação Nacional. Disponível em: http://www.planalto.gov.br/ccivil_03/leis/L9394.htm. Acesso em: 28 de abril de 2020.

BRIZOLA, Jairo; FANTIN, Nádia. Revisão da literatura e revisão sistemática da literatura. Revista RELVA, Juara-MT, v. 3, n. 2, p. 23-39, jul./dez. 2016.

CAZÉ, C.; OLIVEIRA, A. Dança além da visão: possibilidades do corpo cego. Pensar a Prática, v. 11, n. 3, p. 293, dez. 2008.

CUNHA, G. B. Dança inclusiva e deficiência intelectual: um estudo com educandos da rede municipal de ensino de Aparecida de Goiânia. 2017. 96 f. Dissertação (Mestrado em Ensino na Educação Básica) - Universidade Federal de Goiás, Goiânia-GO, 2017.

FALSARELLA, Andrea Pedroni; BERNARDES-AMORIM, Danielle. A importância da dança no desenvolvimento psicomotor de crianças e adolescentes. Conexões, v. 6, p. 306-317, 2008. 
FERREIRA, W. B. Educação Inclusiva: será que sou a favor ou contra uma escola de qualidade para todos? Revista da Educação Especial, p. 40-46, 2005.

GILBERT, Ana Cristina Bohrer; KELLERMAN, Paulo. Geografias corporais: dança, corpo e deficiência. Interface, Botucatu, v. 24, abril. 2020. Disponível em: https://doi.org/10.1590/interface.190603.

HOLANDA, Rafaela Eleutério. Dança-sujeito-encontro: experiências em dança-educação na Escola Parque Anísio Teixeira - Ceilândia/DF. Dissertação (Mestrado Profissional em Arte) Universidade de Brasília, Brasília, 2018.

MARQUES, Isabel. Dançando na escola. Motriz, v. 3, n. 1, jun. 1997.

MARTINS, Maria de Fátima M. Estudos de Revisão de Literatura, 2018.

MEMÓRIA DA ADMINISTRAÇÃO PÚBLICA BRASILEIRA. Imperial Instituto dos Meninos Cegos. Disponível em: http://mapa.an.gov.br/index.php/menu-de-categorias-2/327imperialinstituto-dos-meninos-cegos. Acesso em: 05 de fevereiro de 2020.

MORAN, José Manuel. A educação que desejamos: Novos desafios e como chegar lá. 5 ed. Campinas, SP: Editora Papirus, 2012.

NÓBREGA-THERRIEN, Sílvia Maria; THERRIEN, Jacques. Trabalhos científicos e o Estado da Questão: reflexões teórico-metodológicas. Revista Estudos em Avaliação Educacional, v. 15, n. 30, jul./dez. 2004.

NUNES, Sandra Meyer. Fazer dança e fazer com dança: perspectivas estéticas para os corpos especiais que dançam. Ponto de Vista, Florianópolis, n. 6-7, p. 43-56, 2005.

PAULINO, Belister Rocha. Movimento, arte e expressividade: uma proposta de dança educativa para alunos com deficiência intelectual. Dissertação (Mestrado Profissional em Arte) - Universidade de Brasília, Brasília-DF, 2017.

PINHO, E. P. B. Performances da dança-educação: autonomia e autogovernança. Dissertação (Mestrado em Performance Cultural) - Universidade Federal de Goiás, Goiânia-GO, 2015.

QUADROS, Cláudia Terezinha. Contribuições dos processos coreográficos da dançaeducação à formação docente: ensinar/aprender em coreografias didático-criativas. Tese (Doutorado em Educação) - Programa de Pós-Graduação em Educação, Universidade Federal de Santa Maria, Santa Maria-RS, 2017.

ROTHER, Edna Terezinha. Revisão Sistemática X Revisão Narrativa. Editorial Acta Paul Enferm, 2007.

SANTOS, Rosirene Campêlo dos; FIGUEIREDO, Valéria Maria Chaves. Dança e inclusão no contexto escolar, um diálogo possível. Pensar a Prática, n. 6, p. 107-116, jun./jul. 2003.

SILVA, Aline Maira da. Educação especial e inclusão escolar: história e fundamentos. Curitiba-PR: Editora IBPEX, 2010. 
SIQUEIRA, Denise. Corpo, comunicação e cultura: A dança contemporânea em cena. Campinas-SP: Autores Associados, 2006.

STRAZZACAPPA, Márcia. A educação e a fábrica de corpos: a dança na escola. Cadernos Cedes, ano 21, n. 53, abr. 2001.

\section{Sobre os autores}

Marcus Vinícius Sudário Perez. Licenciando em Artes Cênicas pela Universidade Estadual de Mato Grosso do Sul (UEMS). Acadêmico-pesquisador do Programa de Iniciação Científica (PIBIC) e membro do Grupo de Pesquisa de Poéticas e Educação em Dança (GPPED - Núcleo CRI(s)ES).

E-mail: marcus.sudario.perez@hotmail.com.

Christiane Guimarães de Araújo. Doutorado e Mestrado em Educação pela Universidade Católica Dom Bosco-MS (UCDB). Especialista em Arte Integrativa pela Anhembi Morumbi-SP. Graduada em Dança pela Faculdade de Artes do Paraná (FAP). Docente nos cursos de Artes Cênicas, Dança e Teatro da Universidade Estadual de Mato Grosso do Sul (UEMS). Coordenadora do Grupo de Pesquisa de Poéticas e Educação em Dança (GPPED - Núcleo CRI(s)ES).

E-mail: chris.araujo@ yahoo.com.br. 